\title{
Primary Biliary Cirrhosis Associated with Multiple Myeloma
}

\author{
Haruo Kaneko, Takao Endo, Hirokazu SAitoh, Yasumi Katsuta, Takumi Aramaki \\ and Hirokazu HaYaKawa
}

\begin{abstract}
An association between autoimmune disease and malignancy, in particular lymphoproliferative neoplasms, has been reported, as has an increased incidence of extrahepatic malignancy in primary biliary cirrhosis (PBC). Monoclonal immunoglobulin elevations in $\mathrm{PBC}$ are rare, and there have been only three cases in the literature of PBC associated with multiple myeloma. We describe a patient who was concurrently diagnosed as having $\mathrm{PBC}$ and multiple myeloma, and emphasize the need to consider myeloma when evaluating monoclonal gammopathy in $\mathrm{PBC}$. We also discuss the possible mechanisms for the association of the two conditions.
\end{abstract}

(Internal Medicine 32: 802-805, 1993)

Key words: monoclonal gammopathy, autoimmune disease, malignancy

\section{Introduction}

The etiology of primary biliary cirrhosis $(\mathrm{PBC})$ remains unknown but autoimmune pathogenesis has been suggested (1). Abnormalities of immune function found in PBC include hypergammaglobulinemia, serum autoantibodies and circulating immune complexes as well as the frequent association with presumed autoimmune disorders (2). The hypergammaglobulinemia of PBC is caused by polyclonal elevations of serum immunoglobulins, and monoclonal immunoglobulin elevations are rarely found (2). On the other hand, an association of autoimmune disease with malignancy, in particular lymphoproliferative neoplasms, has been reported (3), as has an increased incidence of extrahepatic malignancy in $\operatorname{PBC}(4,5)$. We describe a patient who had PBC and multiple myeloma concurrently diagnosed, and discuss the possibility of their causal relation.

\section{Case Report}

A 65-year-old man was admitted to Nippon Medical School Hospital on March 10, 1992 for evaluation of renal and liver function disturbances. The patient had been well until 9 months previously, when he passed dark-red urine accompanied by increasing fatigue and low-grade fever over the subsequent three weeks. After a similar episode in the middle of February he visited a nearby hospital, where results of cystoscopic examination were negative. Because biochemical tests of renal and liver function were found to be abnormal, he was referred to our hospital for further evaluation. Liver dysfunction was first pointed out at the age of 59 years, and proteinuria at 61 years.

On physical examination, the patient had anemic and icteric conjunctivas. No cardiac murmurs or rales in the lungs were heard. The liver edge was palpable $5 \mathrm{~cm}$ beneath the right costal margin. There was no peripheral edema or lymphadenopathy.

The urinalysis was positive for protein but negative for Bence-Jones protein; the sediment contained innumerable red cells and 30 to 35 white cells per high-power field. In a 24-hour specimen of urine, the protein content was $1.6 \mathrm{~g}$. The hematocrit value was $27.3 \%$, hemoglobin $9.2 \mathrm{~g} / \mathrm{dl}$, white-cell count 7,100 / $\mathrm{mm}^{3}$ with a normal differential count, platelet count 92,000 / $\mathrm{mm}^{3}$, bleeding time $>5 \mathrm{~min}$, prothrombin time $85 \%$, activated partial-thromboplastin time $34 \mathrm{sec}$, and the erythrocyte sedimentation rate $146 \mathrm{~mm} / \mathrm{h}$. The blood urea nitrogen level was $81 \mathrm{mg} / \mathrm{dl}$, creatinine $9.3 \mathrm{mg} / \mathrm{dl}$, total bilirubin $2.0 \mathrm{mg} / \mathrm{dl}$ and conjugated bilirubin $1.3 \mathrm{mg} / \mathrm{dl}$. Serum aspartate aminotransferase was $40 \mathrm{IU} / \mathrm{l}$, alanine aminotransferase $27 \mathrm{IU} / \mathrm{l}$, lactic dehydrogenase 443 IU/l (normal: 195 to 365), alkaline phosphatase $939 \mathrm{IU} / \mathrm{l}$ (normal: 65 to 205 ) and gamma-glutamyl transpeptidase $932 \mathrm{U} / \mathrm{l}$ (normal: 4 to 50). Serum electrophoresis disclosed an $\mathrm{M}$ component in the gamma region and a total protein level of $6.9 \mathrm{~g} / \mathrm{dl}$ with albumin $3.2 \mathrm{~g} / \mathrm{dl}$, alpha 1 globulin $0.4 \mathrm{~g} / \mathrm{dl}$, alpha 2 globulin $0.5 \mathrm{~g} / \mathrm{dl}$, beta globulin $0.8 \mathrm{~g} / \mathrm{dl}$ and gamma globulin $2.0 \mathrm{~g} / \mathrm{dl}$. Immunoelectrophoresis of the serum (Fig. 1) showed a broad, dense precipitin arc in the gamma region when anti-IgA antiserum was used. An abnormal arc with a configuration similar to that of the IgA arc also appeared in the same region when anti-kappa light chain antiserum was used. Quantification of the immunoglobulins revealed the fol-

From the First Department of Internal Medicine, Nippon Medical School, Tokyo

Received for publication May 17, 1993; Accepted for publication October 12, 1993

Reprint requests should be addressed to Dr. Takao Endo, the First Department of Internal Medicine, Nippon Medical School, 1-1-5 Sendagi, Bunkyo-ku, Tokyo 113 


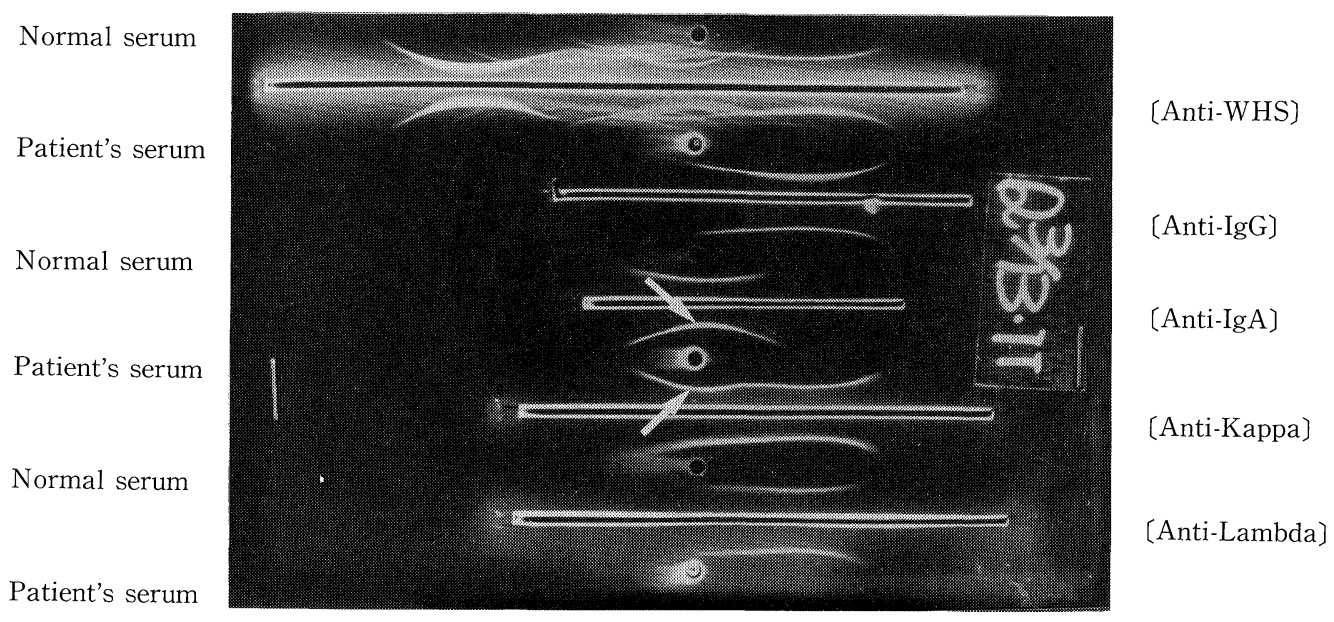

Fig. 1. Immunoelectrophoresis of serum of the patient, as compared with normal serum, showing monoclonal protein of $\operatorname{IgA}$ with kappa light chains (arrows).

lowing: IgA concentration 1,509 mg/dl, IgG $1,794 \mathrm{mg} / \mathrm{dl}$, IgM $531 \mathrm{mg} / \mathrm{dl}, \mathrm{IgD}<0.6 \mathrm{mg} / \mathrm{dl}$ and $\mathrm{IgE} 10.2 \mathrm{IU} / \mathrm{ml}$. Test for cryoglobulin was negative. Microscopic examination of a stained bone marrow smear disclosed marked infiltration by atypical plasma cells (Fig. 2); the percentage of plasma cells was 17.6 and the myeloid to erythroid ratio 4.5:1.0. Most of the plasma cells produced brownish enzyme reaction products when the enzyme-labeled antibody technique with the use of anti-IgA or anti-kappa antibodies was performed. Skeletal roentgenograms showed compression fractures in the bodies of the eleventh and twelfth thoracic and the first lumbar vertebrae, and a diffuse osteoporosis of the spine and pelvis, but no distinct osteolytic lesions or'osteosclerosis. The free thyroxine level was $0.8 \mathrm{ng} /$ $\mathrm{dl}$, the free triiodothyronine $0.7 \mathrm{pg} / \mathrm{ml}$, and the thyroid-stimulating hormone $10.8 \mu \mathrm{U} / \mathrm{ml}$. A test for anti-mitochondrial antibody was positive in a titer of greater than 1:320. Tests for antinuclear, anti-smooth muscle, anti-microsomal and antithyroglobulin antibodies were negative as well as serological markers for hepatitis $\mathrm{B}$ and $\mathrm{C}$ viruses. A computed tomography of the abdomen revealed mild hepatosplenomegaly and ascitic fluid. Upper gastrointestinal endoscopy demonstrated distended esophageal varices. An appropriate liver biopsy specimen for histological diagnosis could not be obtained with the use of a transjugular approach. Ultrasound- or laparoscopy-guided liver biopsy was not performed because of the presence of ascitic fluid and prolonged bleeding time. The clinical diagnoses were PBC associated with multiple myeloma and primary hypothyroidism. The diagnosis of $\mathrm{PBC}$ was based on raised levels of serum alkaline phosphatase and gamma-glutamyl transpeptidase, a high serum IgM, and a highly positive serum mitochondrial antibody test. Hemodialysis was performed for renal failure, and general measures were taken towards the PBC and myeloma, including control of pruritus. Systemic chemotherapy of myeloma was not initiated because of the patient's disagreement. The laboratory data 8 months after the diagnosis were the following: IgA concentration 1,531 mg/dl, hemoglobin $9.0 \mathrm{~g} / \mathrm{dl}$

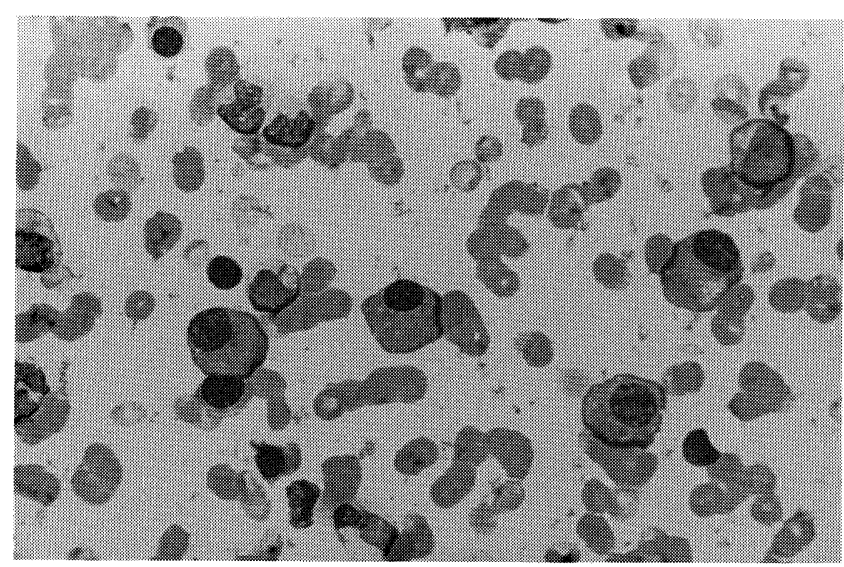

Fig. 2. Bone marrow aspirate showing marked infiltration by myeloma cells $(\times 1,000)$.

and creatinine $8.9 \mathrm{mg} / \mathrm{dl}$. On January 2, 1993, he died of pneumonia. Autopsy was not permitted.

\section{Discussion}

The hypergammaglobulinemia of $\mathrm{PBC}$ is of polyclonal variety, and has been attributed to polyclonal B cell activators, defects in hepatic clearance of antigens, or immunologic imbalance between lymphocyte suppressor and helper functions (2). Benign monoclonal gammopathy is rare in $\mathrm{PBC}$, occurring in $1.8 \%$ of cases in one series (2). However, to our knowledge, this is the fourth reported case of $\mathrm{PBC}$ associated with multiple myeloma (6-8) (Table 1). Half of the patients were male, as opposed to the female predominance $(90 \%)$ in PBC without malignancy (9). The median age at the time of diagnosis of $\mathrm{PBC}$ was 64.5 years, which approximates that of $\mathrm{PBC}$ with other forms of malignancy (62.5 years) (4), and is a somewhat older age when compared with that of PBC without malignancy (40 


\section{KANEKO et al}

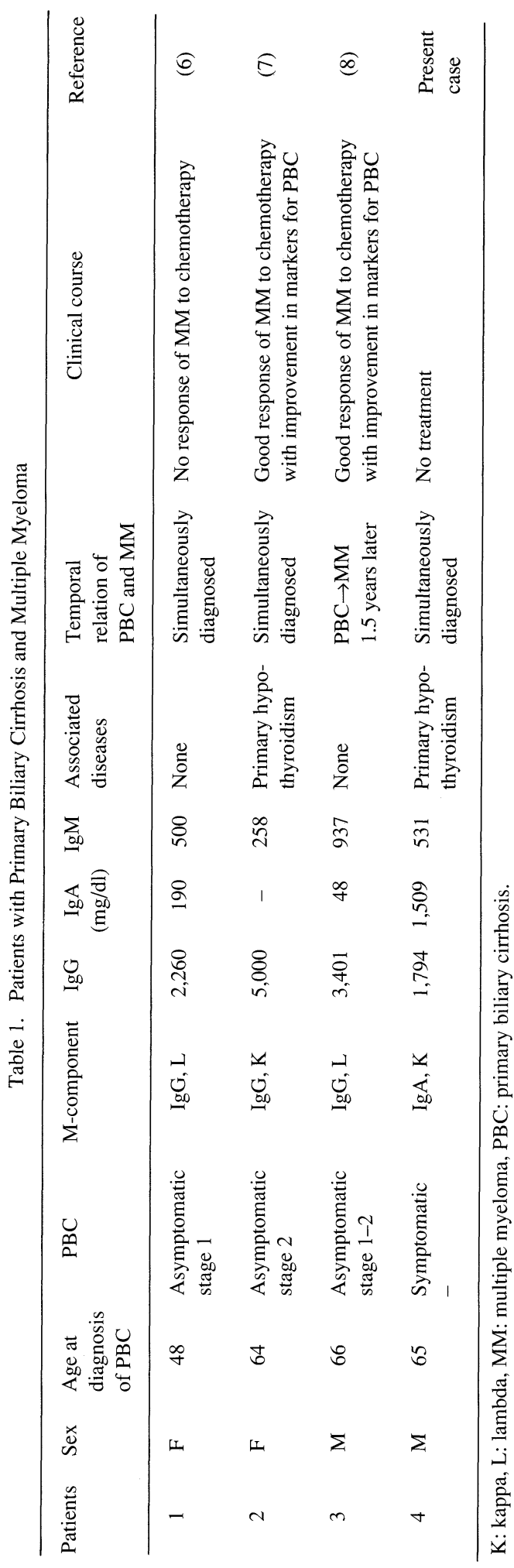

to 59 years) (9). Three of the four patients were asymptomatic, had an early histologic stage (stages 1 and 2) and monoclonal protein of IgG with kappa or lambda light chains. Two patients also had primary hypothyroidism. In contrast to "classic" myeloma, in which the normal immunoglobulin concentration is usually very low (10), there was no concomitant suppression in the synthesis of other normal immunoglobulins in these patients. All the patients showed increased serum IgM concentrations. Only one patient with IgG myeloma had a low level of serum IgA. Thus, in the presence of monoclonal immunoglobulin elevations in patients with $\mathrm{PBC}$, the possibility of an association with multiple myeloma, in addition to benign monoclonal gammopathy, should be considered, even when normal immunoglobulin concentration is not reduced.

Whether there is a causal relationship of PBC and multiple myeloma is unknown because the insidious onset and chronic nature of these diseases make it impossible to evaluate the temporal relationship between the two conditions. In the review of patients with $\mathrm{PBC}$, three of the four had a concurrently diagnosed myeloma. In two patients, an improvement in markers for $\mathrm{PBC}$, including the serum alkaline phosphatase and serum IgMlevel, was observed after chemotherapy of myeloma. Thus, this close temporal relation suggests a causal relationship between the two diseases. Although the precise mechanisms for the association of $\mathrm{PBC}$ and myeloma are not clear, there are several possible explanations. 1) A monoclonal gammopathy may develop from a polyclonal variety in the course of PBC. Zawadzki and Edwards (11) described two patients with alcoholic cirrhosis in whom transformation of polyclonal to monoclonal gammopathy was documented. One of these patients died of overt multiple myeloma. Whether this transformation is a result of chronic antigenic stimulation is unknown (12). 2) PBC and associated myeloma may share a common pathogenesis resulting from abnormal immune function. The cause of PBC is not well understood, but alterations of both cellular and humoral immune function have been suggested to play a major role in its pathogenesis (1). Thus, the two diseases could stem from the altered immune system and impaired immunological surveillance, resulting in a hampered ability to suppress and eliminate the emergence and proliferation of neoplastic cells $(4,5)$.

Acknowledgment: We gratefully acknowledge Mrs. Tamiko Kikuchi for secretarial assistance, and Dr. Mari Watanabe for her advice in reviewing the manuscript.

\section{References}

1) Sherlock S. Diseases of the Liver and Biliary System, 8th ed. Blackwell Scientific Publications, Oxford, 1989, p. 273.

2) Culp KS, Fleming CR, Duffy J, et al. Autoimmune associations in primary biliary cirrhosis. Mayo Clin Proc 57: 365, 1982.

3) Miller DG. The association of immune disease and malignant lymphoma. Ann Intern Med 66: 507, 1967.

4) Mills PR, Boyle P, Quigley E, et al. Primary biliary cirrhosis: an increased incidence of extrahepatic malignancies? J Clin Pathol 35: 541, 1982.

5) Wolke AM, Schaffner F, Kapelman B, et al. Malignancy in primary biliary cirrhosis. High incidence of breast cancer in affected women. Am 


\section{PBC with Multiple Myeloma}

J Med 76: 1075, 1984.

6) Blade J, Montserrat E, Bruguera M, et al. Multiple myeloma in primary biliary cirrhosis. Scand J Haematol 26: 14, 1981.

7) Washio $\mathrm{M}$, Tsuji $\mathrm{H}$, Murai $\mathrm{K}$, et al. A case of asymptomatic primary biliary cirrhosis associated with multiple myeloma and atrophic thyroiditis. Nippon Naika Gakkai Zasshi 76: 528, 1987.

8) Fujii H, Yashige H. Multiple myeloma of IgG-lambda type associated with asymptomatic primary biliary cirrhosis. Jpn J Clin Hematol 30: 1886, 1989.
9) Sherlock S, Scheuer PJ. The presentation and diagnosis of 100 patients with primary biliary cirrhosis. N Engl J Med 289: 674, 1973.

10) Bergsagel DE. Plasma Cell Myeloma. in: Hematology, Williams WJ, Beutler E, Erslev AJ, Lichtman MA, eds. McGraw-Hill Publishing Co., New York, 1990, p. 1114.

11) Zawadzki ZA, Edwards GA. Dysimmunoglobulinemia associated with hepatobiliary disorders. Am J Med 48: 196, 1971.

12) Slavin S, Zlotnick A, Levij IS, et al. Clinical implications of monoclonal gammopathy in chronic liver disease. Dig Dis 19: 223, 1974. 